\title{
Ozone pollution around a coastal region of South China Sea: interaction between marine and continental air
}

\section{Hao Wang et al.}

Correspondence to: Hai Guo (ceguohai@ polyu.edu.hk) and Fei Jiang (jiangf@nju.edu.cn) 
Table S1. Gradient separation of $\mathrm{C}_{1}-\mathrm{C}_{9}$ aldehyde and ketone derivatives.

\begin{tabular}{ll} 
Column & Nava-Pak C18 $3.9 \times 150 \mathrm{~mm}$ \\
\hline Mobile phase & A: Water/Acetonitrile/Tetrahydrofuran 60/30/10 \\
\hline Gradient & B: Water/Acetonitrile 40/60 \\
\hline Flow rate & $100 \%$ A for 2 min then a linear gradient from $100 \%$ A to \\
& $100 \%$ B in 18 min, $100 \%$ B for $4 \mathrm{~min}$ \\
\hline Injection volume & $20 \mu \mathrm{L}$ \\
\hline Detection & Absorbance at $360 \mathrm{~nm}$ \\
\hline
\end{tabular}

Table S2. Description of parameters used in WRF-CMAQ simulation.

\begin{tabular}{|c|c|c|}
\hline Model & Parameters & Value \\
\hline \multirow{9}{*}{ WRF(v3.7.1) } & Microphysics & $\begin{array}{l}\text { WRF Single-Moment 3-class } \\
\text { scheme }\end{array}$ \\
\hline & Longwave Radiation & RRTM scheme \\
\hline & Shortwave Radiation & Dudhia scheme \\
\hline & Surface Layer & MM5 similarity \\
\hline & Land Surface & Noah Land Surface Model \\
\hline & Planetary Boundary layer & Yonsei University scheme \\
\hline & Cumulus Parameterization & Kain-Fritsch scheme \\
\hline & Diffusion Option & Simple diffusion \\
\hline & K Option & 2d Deformation \\
\hline \multirow{15}{*}{ CMAQ(4.7.1) } & ModDriver & ctm_yamo \\
\hline & ModInit & init_yamo \\
\hline & ModAdjc & $\begin{array}{c}\text { // yamo option does not need } \\
\text { denrate }\end{array}$ \\
\hline & ModCpl & gencoor \\
\hline & ModHadv & hyamo \\
\hline & ModVadv & vyamo \\
\hline & ModHdiff & multiscale \\
\hline & ModVdiff & acm2_inline \\
\hline & ModPhot & phot \\
\hline & ModChem & ebi_cb05cl_ae5 \\
\hline & ModAero & aero5 \\
\hline & ModCloud & cloud_acm_ae5 \\
\hline & ModPa & pa \\
\hline & ModUtil & util \\
\hline & Mechanism & cb05cl_ae5_aq \\
\hline
\end{tabular}


Table S3. Index of agreement (IOA) between the simulated and observed meteorological parameters and air pollutants. IOA was calculated using the equation in Willmott (1982). Within the range of $0-1$, higher IOA represents better agreement between the simulated and observed values.

\begin{tabular}{lll}
\hline & $\mathrm{TC}$ & $\mathrm{WS}$ \\
\hline Temperature & 0.81 & 0.84 \\
Wind speed & 0.56 & 0.54 \\
Wind direction & 0.60 & 0.51 \\
Relative humidity & 0.79 & 0.77 \\
$\mathrm{CO}$ & 0.88 & 0.87 \\
$\mathrm{NO}_{\mathrm{x}}$ & 0.50 & 0.62 \\
$\mathrm{O}_{3}$ & 0.81 & 0.81 \\
\hline
\end{tabular}

Table S4. Summary of $\mathrm{O}_{3}$ episode days at WS and TC during the sampling period.

\begin{tabular}{|c|c|c|c|c|c|c|c|}
\hline No. & Description & Date & SLB & WS & $\mathrm{O}_{3 \_} \mathrm{MAX}$. & $\mathrm{TC}$ & $\mathrm{O}_{3 \_} \mathrm{MAX}$. \\
\hline 0 & Typhoon- & 0820 & $\mathrm{Y}$ & near- $\mathrm{O}_{3}$ episode & 92.6 & near- $\mathrm{O}_{3}$ episode & 87.1 \\
\hline 1 & $\begin{array}{l}\text { related } \\
\text { (Trami) }\end{array}$ & 0821 & $\mathrm{~N}$ & episode & 173.0 & episode & 159.9 \\
\hline 2 & Typhoon- & 0920 & $\mathrm{~N}$ & - & 61.4 & episode & 126.8 \\
\hline 3 & $\begin{array}{l}\text { related } \\
\text { (Usagi) }\end{array}$ & 0921 & $\mathrm{~N}$ & episode & 116.0 & - & 69.3 \\
\hline 4 & Typhoon- & 0927 & $\mathrm{Y}$ & near- $\mathrm{O}_{3}$ episode & 85.4 & episode & 102.4 \\
\hline 5 & $\begin{array}{l}\text { related } \\
\text { (Wutip) }\end{array}$ & 0928 & $\mathrm{Y}$ & episode & 109.4 & - & 71.8 \\
\hline 6 & & 1001 & $\mathrm{~N}$ & near- $\mathrm{O}_{3}$ episode & 89.8 & episode & 107.5 \\
\hline 7 & & 1002 & $\mathrm{Y}$ & episode & 126.9 & near- $\mathrm{O}_{3}$ episode & 91.7 \\
\hline 8 & & 1003 & $\mathrm{Y}$ & episode & 119.1 & episode & 121.2 \\
\hline 9 & $\mathrm{O}_{3}$ episode & 1004 & $\mathrm{Y}$ & episode & 121.3 & episode & 119.7 \\
\hline 10 & event I & 1005 & $\mathrm{Y}$ & episode & 163.2 & episode & 143.1 \\
\hline 11 & & 1006 & $\mathrm{~N}$ & episode & 151.9 & episode & 119.7 \\
\hline 12 & & 1007 & $\mathrm{~N}$ & episode & 118.7 & near- $\mathrm{O}_{3}$ episode & 89.7 \\
\hline 13 & & 1008 & $\mathrm{~N}$ & episode & 138.3 & near- $\mathrm{O}_{3}$ episode & 84.1 \\
\hline 14 & typhoon- & 1011 & $\mathrm{Y}$ & episode & 130.8 & episode & 130.4 \\
\hline 15 & related (Nari) & 1012 & $\mathrm{Y}$ & near- $\mathrm{O}_{3}$ episode & 99.1 & near- $\mathrm{O}_{3}$ episode & 90.2 \\
\hline 16 & & 1019 & $\mathrm{Y}$ & episode & 155.0 & episode & 117.7 \\
\hline 17 & & 1020 & $\mathrm{Y}$ & episode & 122.1 & episode & 120.2 \\
\hline 18 & & 1021 & $\mathrm{Y}$ & episode & 124.0 & episode & 144.7 \\
\hline 19 & & 1022 & $\mathrm{~N}$ & episode & 148.5 & episode & 104.4 \\
\hline 20 & $\mathrm{O}_{3}$ episode & 1023 & $\mathrm{~N}$ & episode & 152.3 & episode & 119.2 \\
\hline 21 & & 1024 & $\mathrm{~N}$ & episode & 148.1 & episode & 116.1 \\
\hline 22 & & 1025 & $\mathrm{~N}$ & episode & 135.8 & near- $\mathrm{O}_{3}$ episode & 89.1 \\
\hline 23 & & 1026 & $\mathrm{~N}$ & episode & 105.3 & episode & 117.2 \\
\hline 24 & & 1027 & $\mathrm{~N}$ & episode & 106.2 & near- $\mathrm{O}_{3}$ episode & 99.3 \\
\hline 25 & typhoon- & 1101 & $\mathrm{Y}$ & near- $\mathrm{O}_{3}$ episode & 83.2 & episode & 106.5 \\
\hline 26 & $\begin{array}{l}\text { related } \\
\text { (Krosa) }\end{array}$ & 1102 & $\mathrm{~N}$ & near- $\mathrm{O}_{3}$ episode & 95.6 & - & 35.1 \\
\hline 27 & & 1115 & $\mathrm{~N}$ & episode & 109.8 & - & 66.2 \\
\hline
\end{tabular}

Note: $\mathrm{An}_{3}$ episode day was defined when the peak one-hour averaged $\mathrm{O}_{3}$ mixing ratio exceeded 100 ppbv (Level II of China National Ambient Air Quality Standard). A near- $\mathrm{O}_{3}$ episode days was defined when the peak hourly average $\mathrm{O}_{3}$ mixing ratio was lower than 100 ppbv but higher than 80 ppbv (Level I of China National Ambient Air Quality Standard). 
Table S5. Statistics (Mean $\pm 95 \%$ C.I) of the top 10 NMHC and the top 3 carbonyl species observed at TC and WS during $\mathrm{O}_{3}$ episodes and non- episodes.

\begin{tabular}{lcccc}
\hline Compound & \multicolumn{1}{c}{ TC } & \multicolumn{2}{l}{ WS } \\
\hline Ethane & $2179 \pm 222$ & $1852 \pm 256$ & $2077 \pm 182$ & $1456 \pm 167$ \\
Propane & $1966 \pm 277$ & $1572 \pm 207$ & $1523 \pm 126$ & $866 \pm 126$ \\
Isobutane & $1944 \pm 371$ & $1433 \pm 166$ & $1559 \pm 167$ & $810 \pm 115$ \\
Acetylene & $2083 \pm 165$ & $1316 \pm 145$ & $1805 \pm 133$ & $1086 \pm 122$ \\
Toluene & $1829 \pm 365$ & $1357 \pm 254$ & $1737 \pm 388$ & $703 \pm 183$ \\
$n$-Butane & $1437 \pm 163$ & $1336 \pm 148$ & $1160 \pm 145$ & $480 \pm 113$ \\
$n$-Hexane & $733 \pm 329$ & $1351 \pm 443$ & $980 \pm 299$ & $447 \pm 121$ \\
Ethene & $1140 \pm 167$ & $1077 \pm 171$ & $826 \pm 99$ & $691 \pm 94$ \\
Isopentane & $964 \pm 145$ & $813 \pm 123$ & $918 \pm 99$ & $523 \pm 96$ \\
Benzene & $614 \pm 49$ & $428 \pm 51$ & $587 \pm 47$ & $381 \pm 44$ \\
Formaldehyde & $5068 \pm 454$ & $3522 \pm 286$ & $4257 \pm 355$ & $2471 \pm 180$ \\
Acetone & $5064 \pm 831$ & $3367 \pm 445$ & $3984 \pm 287$ & $2086 \pm 162$ \\
Acetaldehyde & $1807 \pm 162$ & $1241 \pm 115$ & $1618 \pm 133$ & $920 \pm 105$ \\
\hline
\end{tabular}




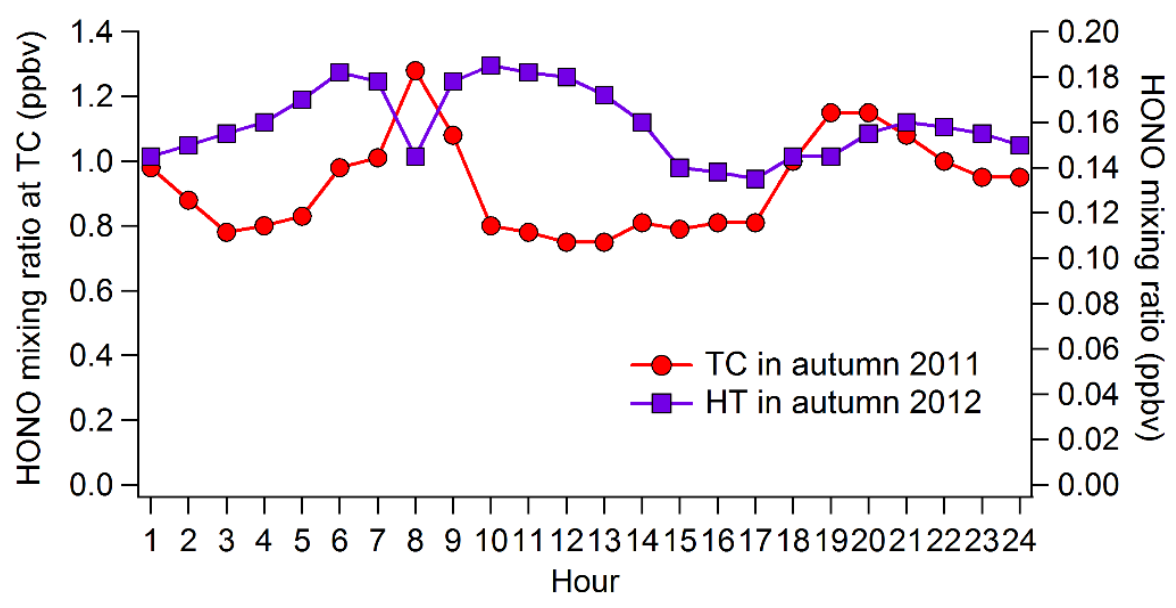

Figure S1 Average diurnal profiles of HONO observed at TC in autumn 2011 and at a coastal background site (Hok Tsui, HT) in southeast Hong Kong in autumn 2012.

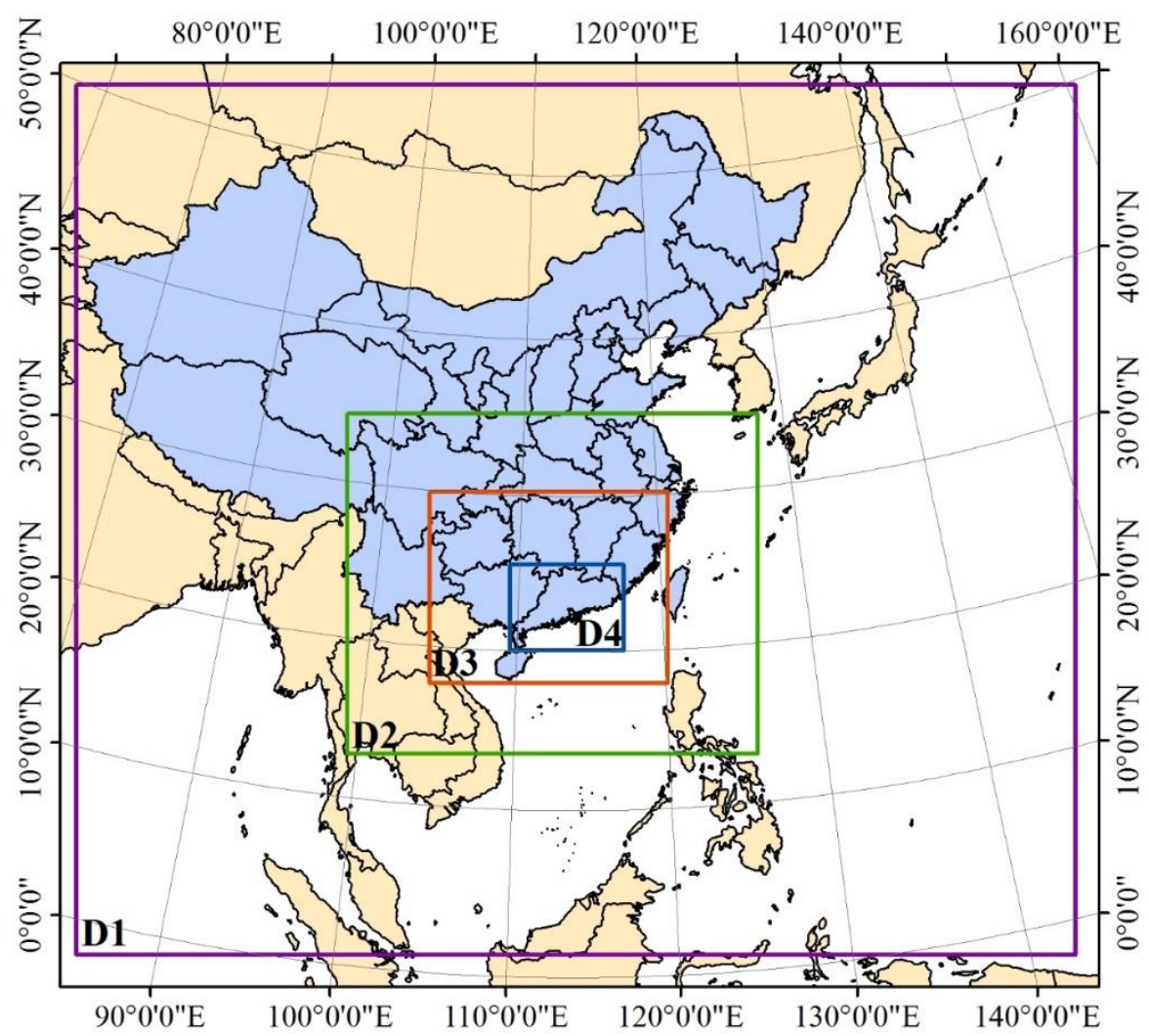

Figure S2 Nesting domain settings of the WRF model. D1, D2, D3 and D4 inside the figure denote domain 1, 2, 3 and 4, respectively. The outermost domain (D1) covers the entire China and East Asia with the resolution of $81 \mathrm{~km} \times 81 \mathrm{~km}$ and $89 \times 78$ grids. D2 covers South China with the resolution of $27 \mathrm{~km} \times 27 \mathrm{~km}$ and $109 \times 91$ grids. D3 covers Guangdong province and the surrounding areas with the resolution of $9 \mathrm{~km} \times 9 \mathrm{~km}$ and $187 \times 151$ grids. The innermost domain (D4) covers Pearl River Delta region with the resolution of $3 \mathrm{~km} \times 3$ $\mathrm{km}$ and $186 \times 150$ grids. 
WS
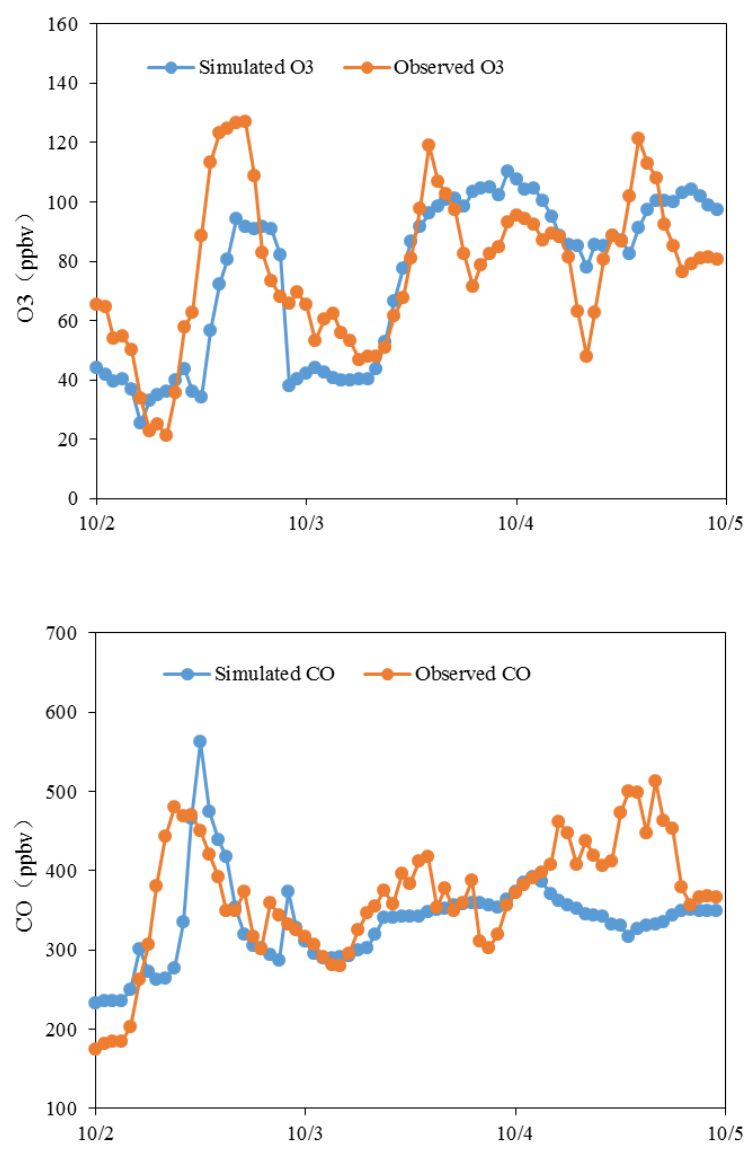

TC
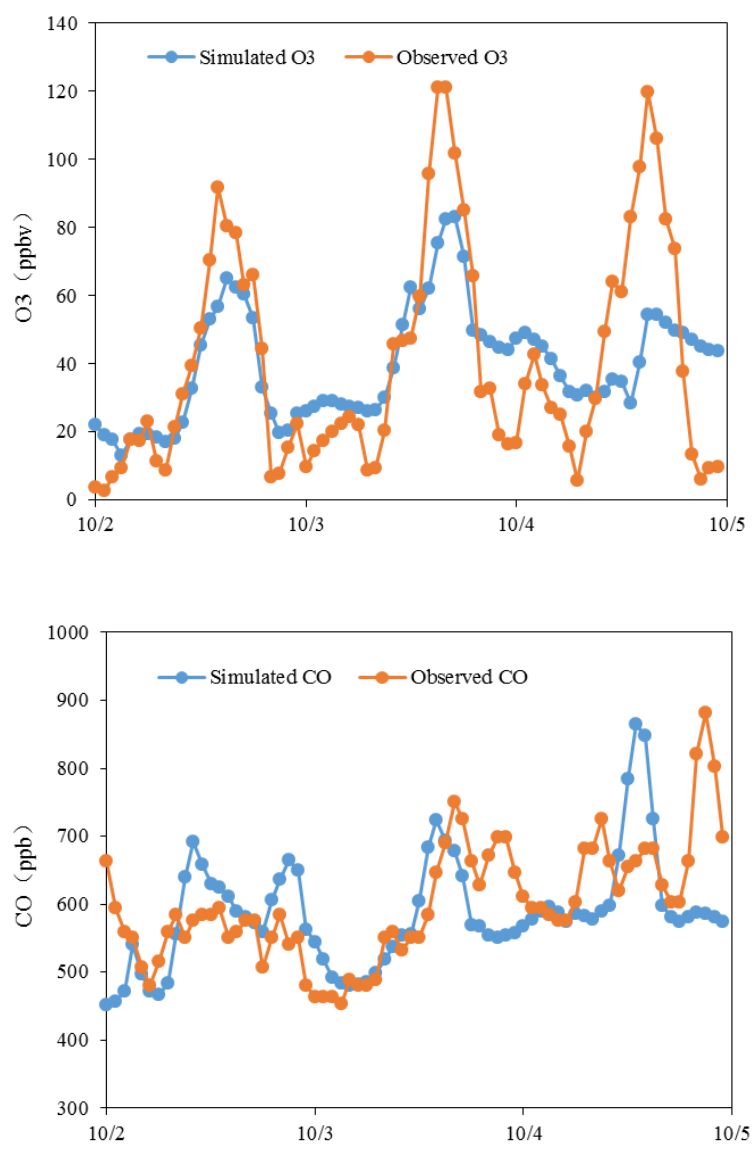

Figure S3. Time series of the WRF-CMAQ simulated and the observed $\mathrm{CO}$ and $\mathrm{O}_{3}$ at WS (left panel) and TC (right panel) during a typical $\mathrm{O}_{3}$ episode on Oct. 2-4, 2013.

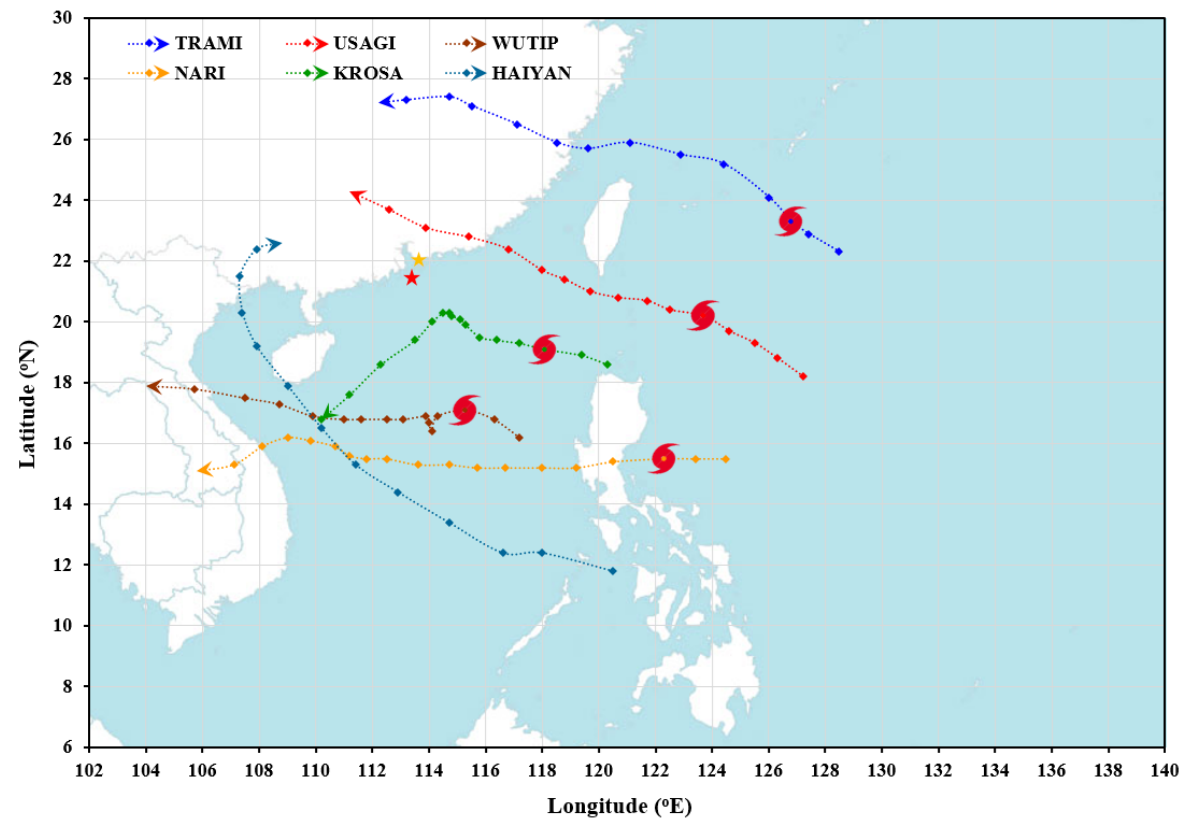

Figure S4. Track of typhoons during the sampling period. The typhoon labels mark the positions when $\mathrm{O}_{3}$ episodes occur in Hong Kong. The dots represent intermediate 6-hourly positions. 

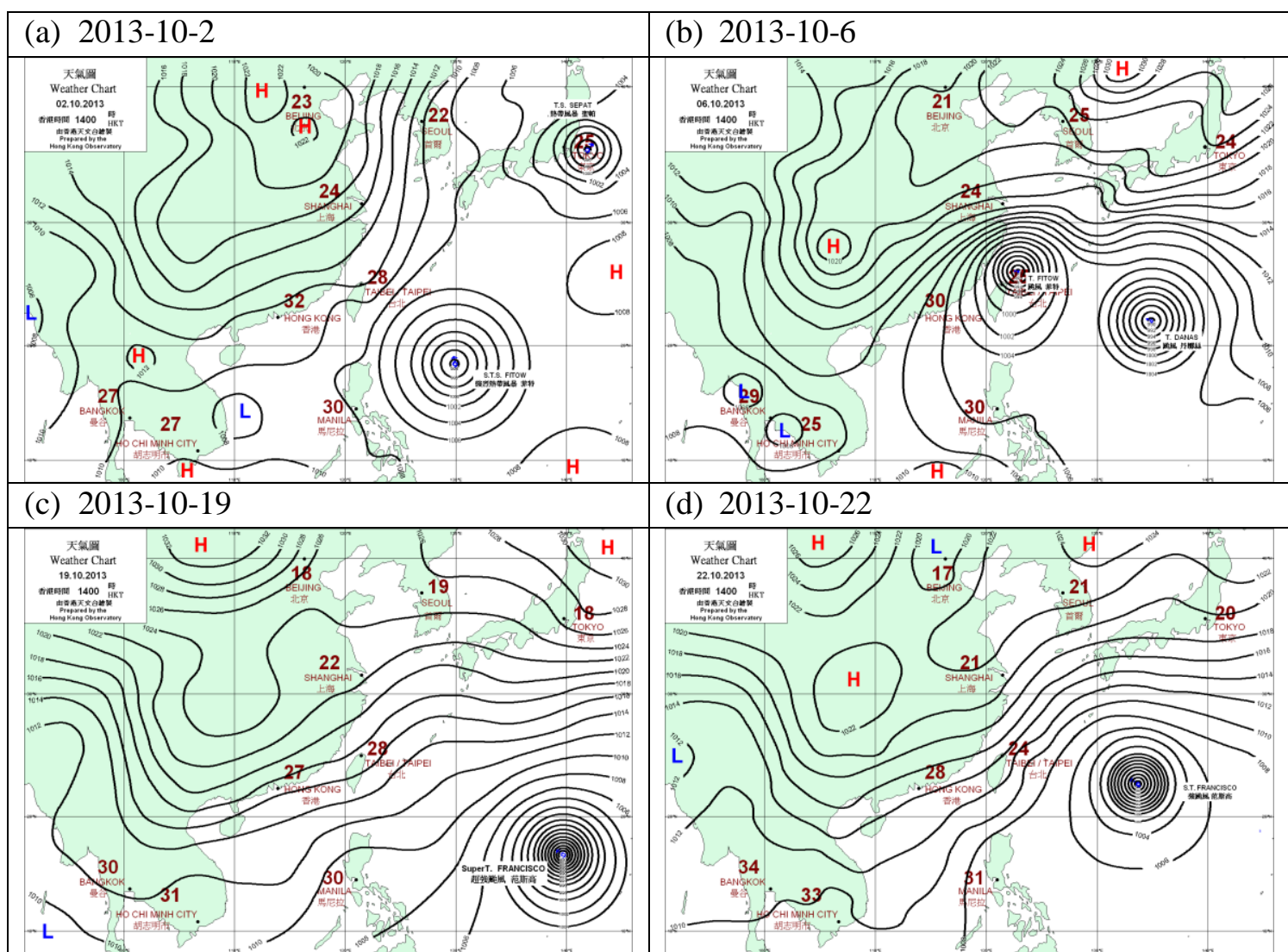

(d) 2013-10-22

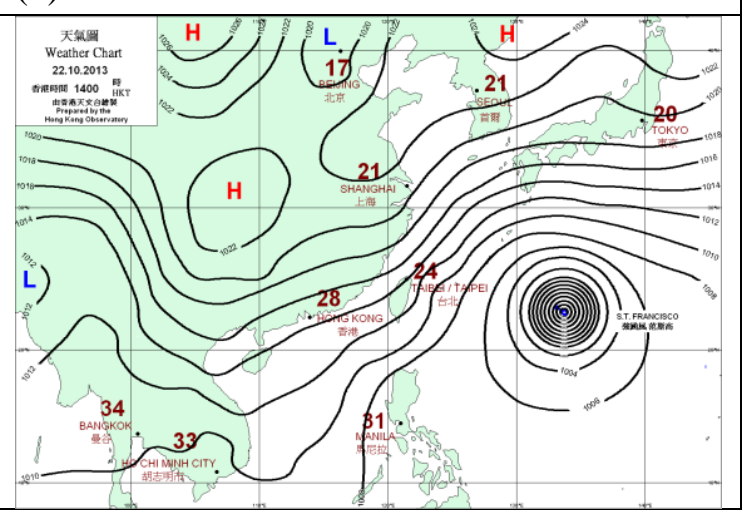

Figure S5. Selected examples of weather charts at 6 am during Continental High Pressure in October 2013. (a) \& (c) Continental high pressure systems formed far away from the coastal areas and caused SLBs related $\mathrm{O}_{3}$ episodes; (b) \& (d) Continental high pressure systems approaching to the coastal areas and caused $\mathrm{O}_{3}$ episodes not related to SLBs; The maps are courtesy provided by Hong Kong Observatory. 

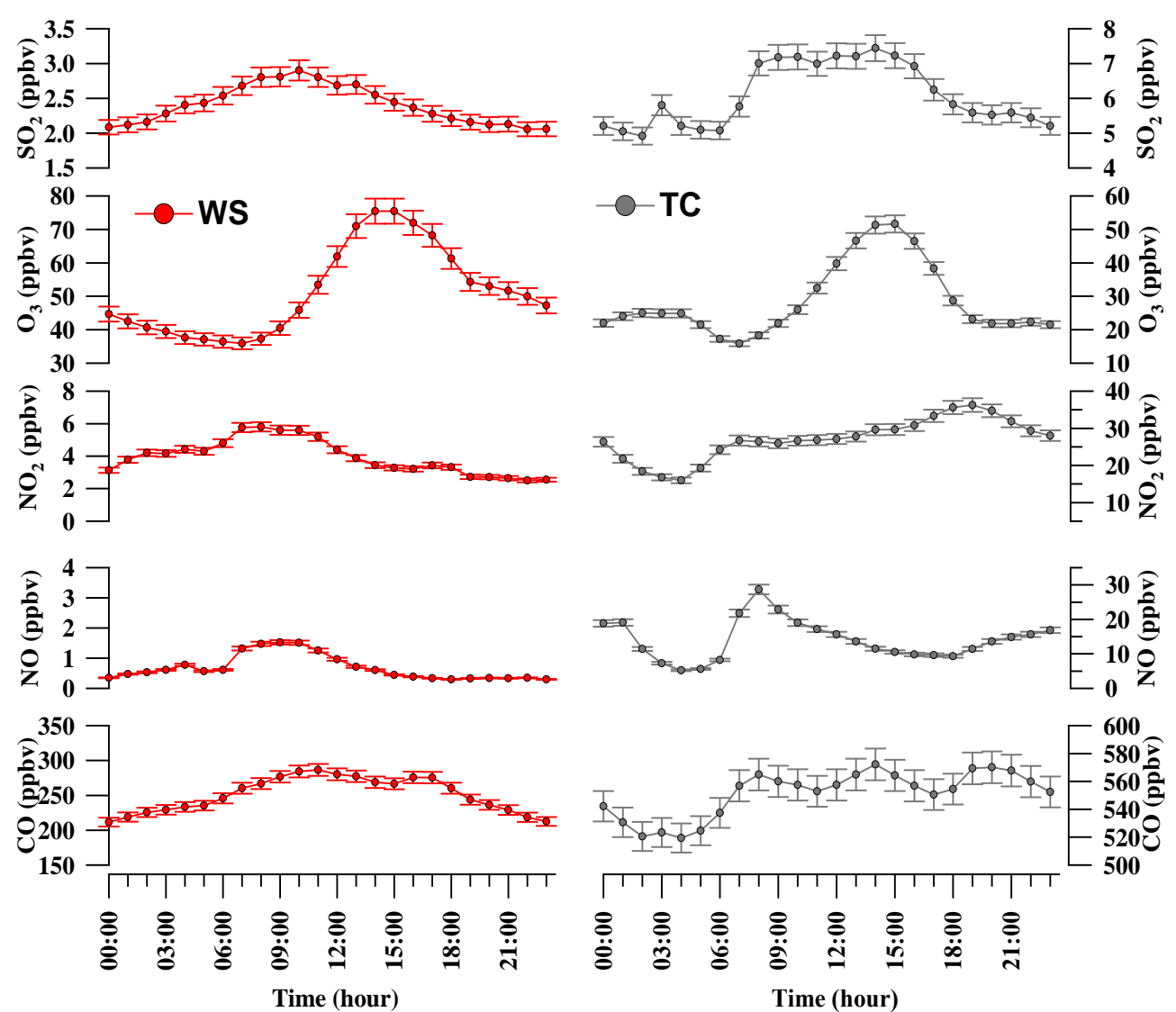

Figure S6. Diurnal variations of trace gases measured at WS and TC. 


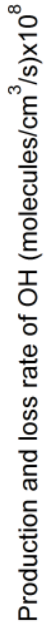

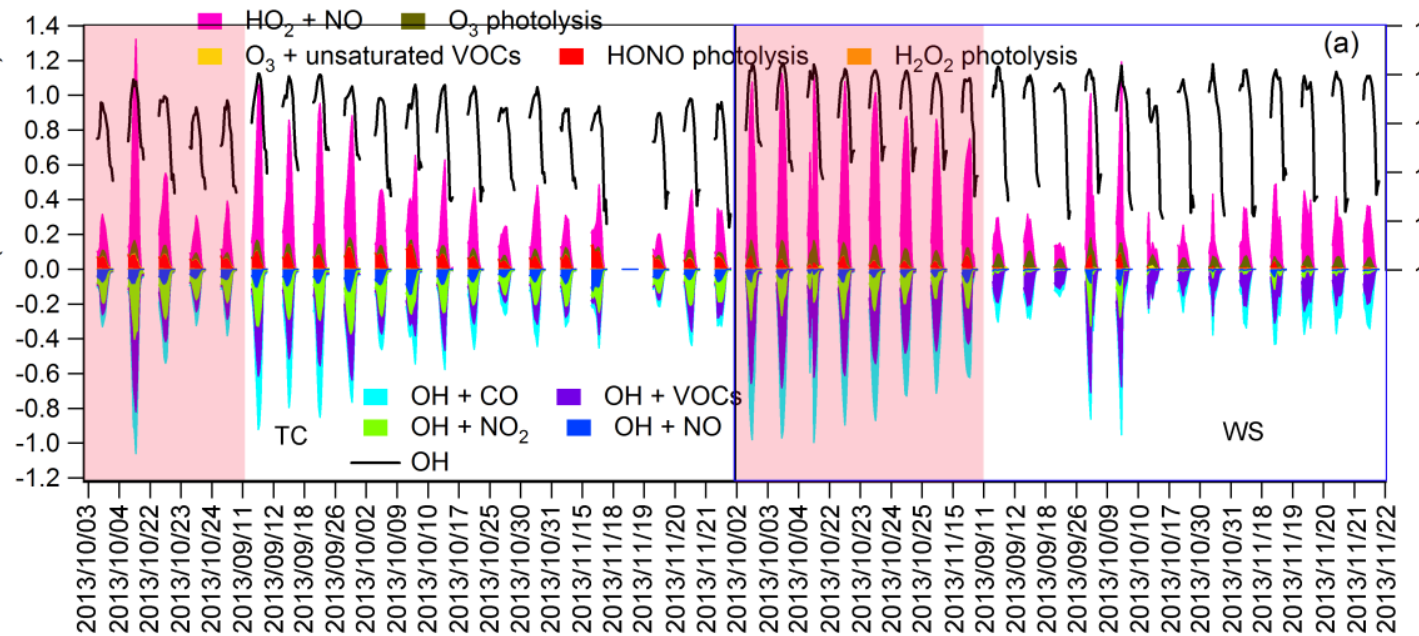
Date
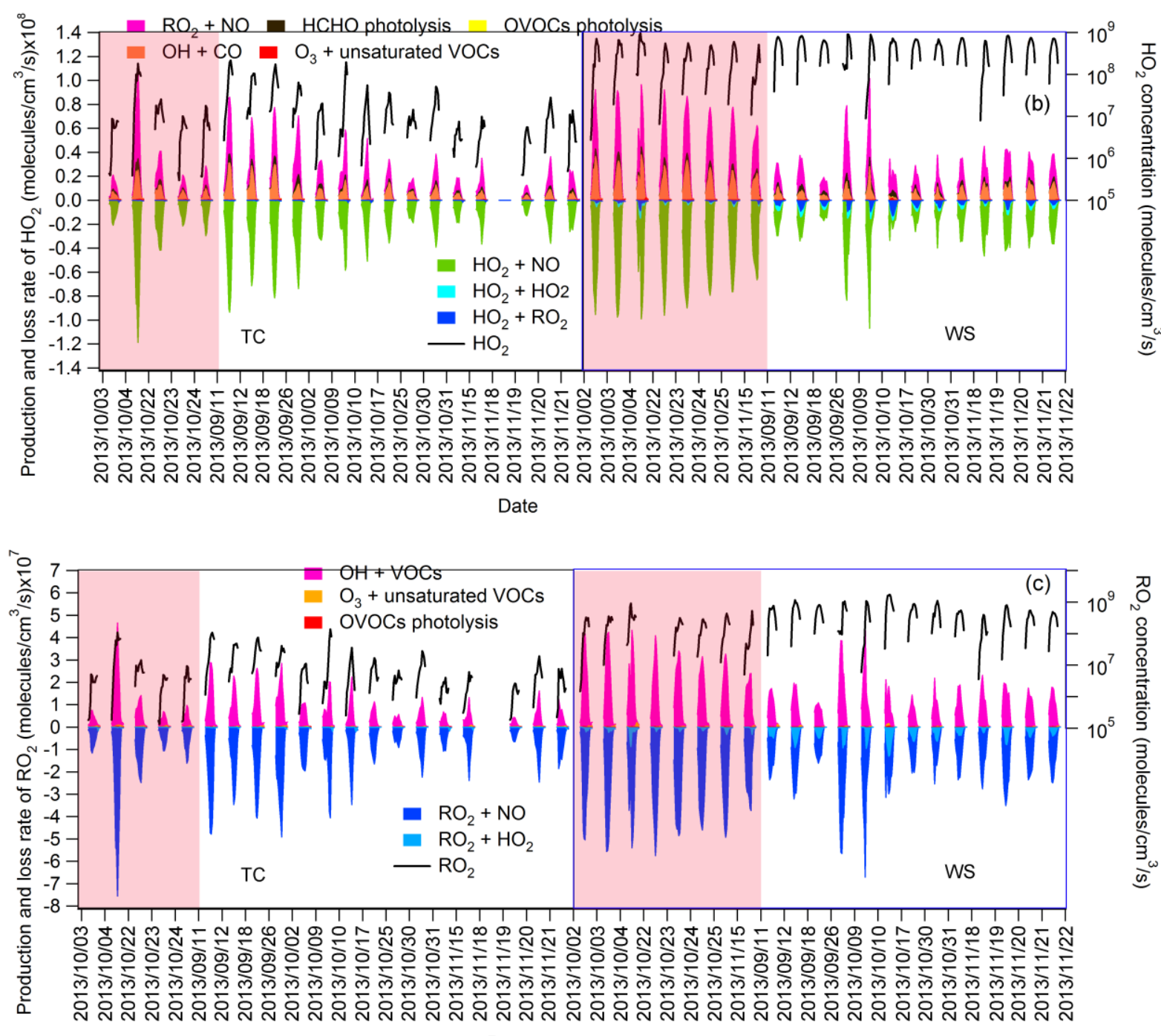
Date

Figure S7. Daytime (7:00-19:00 LT) variations of the simulated production and loss rate of (a) $\mathrm{OH}$, (b) $\mathrm{HO}_{2}$ and (c) $\mathrm{RO}_{2}$ at TC (left panel) and WS (right panel). $\mathrm{O}_{3}$ episode days are highlighted in red background. The dates are not consecutive due to the discontinuous canister sampling of VOCs. 


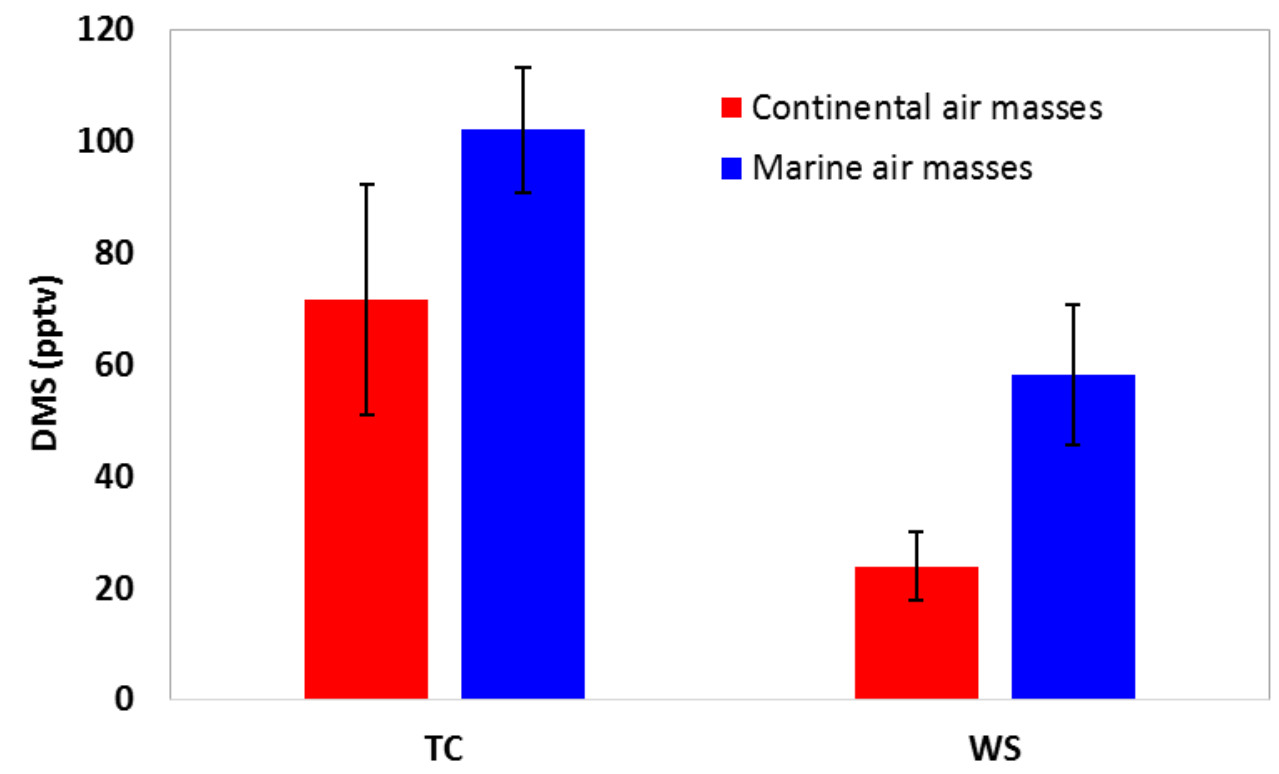

Figure S8 Average concentrations of dimethyl sulfide (DMS) observed at TC and WS when continental or marine air masses dominated. 


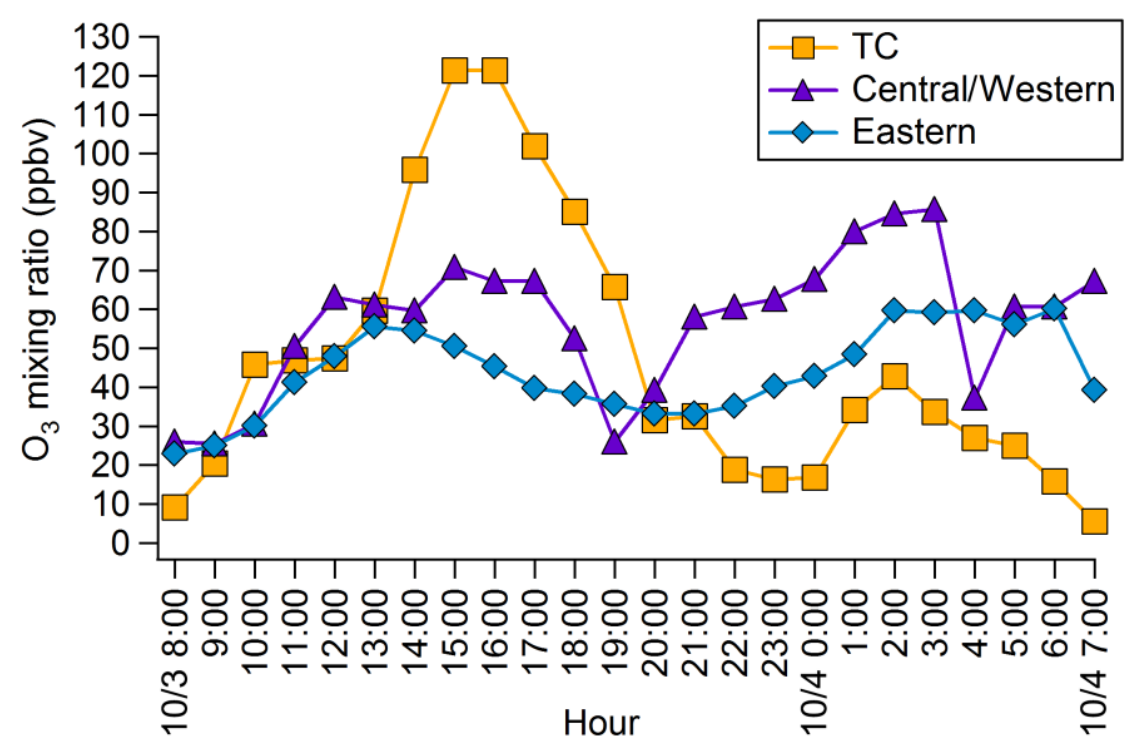

Figure S9. Hourly average $\mathrm{O}_{3}$ observed at TC, Central/Western and Eastern from 08:00 on 3 October to 07:00 on 4 October. The three sites were located in southern Hong Kong, which were all non-roadside sites. Detailed information can be found on the website of HKEPD (http://www.aqhi.gov.hk/en/monitoring-network/air-quality-monitoringstations9c57.html?stationid=81). 